\title{
Female type cystic hyperplasia in a male breast
}

\author{
John McClure, S.S. Banerjee and D.G.D. Sandilands ${ }^{1}$ \\ Departments of Histopathology and 'Surgery, The University Hospital of South Manchester, Nell Lane, West \\ Didsbury, Manchester M20 8LR, UK.
}

\begin{abstract}
Summary: A 28 year old man had a swelling of the right breast. He was phenotypically and karyotypically a normal male. Microscopic examination of the excised specimen showed the pattern of cystic hyperplasia identical to that commonly seen in the female breast. Numerous cysts were grouped in a lobular pattern and their lining showed apocrine metaplasia. There was extensive background fibrosis, some mammary duct ectasia and some features consistent with the more classical microscopic appearances of gynaecomastia. Whilst some of the features noted above are sometimes seen in gynaecomastia the presence of the full range of the features of cystic hyperplasia is distinctly unusual in the male.
\end{abstract}

\section{Introduction}

Lesions of the male breast are relatively uncommon, the more usual being gynaecomastia and carcinoma. This limited spectrum of disease is illustrated by the fact that only a few cases of nipple adenoma (Waldo $e t$ al., 1975), phyllodes tumour (Reingold \& Ascher, 1970; Pantoja et al., 1976), mammary duct ectasia (Tedeschi \& McCarthy, 1974; Mansel \& Morgan, 1979) and a leiomyosarcoma of the nipple (Hernandez, 1978) have been reported. The present account describes the presence of cystic hyperplasia in the breast of a phenotypically and karyotypically normal male. When shown to other pathologists without revealing the patient's gender they all assumed that the material was derived from a female breast. Such a florid lesion is distinctly uncommon in the male breast.

\section{Case report}

A 28 year old man was admitted to hospital with a five year history of swelling and occasional discomfort in the right breast. There was no history of local trauma, alcohol abuse or drug taking. Clinical examination confirmed a right sided breast enlargement which was considered to be a gynaecomastia. The secondary sexual characteristics were of otherwise normal development. A right subcutaneous simple mastectomy was performed through an inframammary incision with nipple preservation.

Correspondence: J. McClure, B.Sc., M.D., M.R.C.Path., Department of Histopathology, UHSM, Nell Lane, West Didsbury, Manchester M20 8LR, UK.

Accepted: 13 August 1984
In the light of subsequent histopathological findings further investigations were performed. X-rays of the pituitary fossa and chest were normal as were the liver function tests, serum prolactin, testosterone and oestrogen. Chromosomal studies showed a normal male karyotype.

\section{Pathological findings}

Two portions of tissue one $95 \times 65 \times 30 \mathrm{~mm}$ the other $55 \times 40 \times 18 \mathrm{~mm}$ were submitted for examination. Macroscopically there were irregular fibrotic zones and numerous cystic spaces $1-2 \mathrm{~mm}$ in diameter.

Microscopically there was background fibrosis (Figure 1). There was extensive cystic change and the cysts were generally grouped in a lobular pattern (Figure 2). They were extensively lined by the apocrine type of epithelium. There was also lobule formation with prominent focal epitheliosis. There was no evidence of malignancy. There was some ductal dilatation with intraluminal accumulation of foam cells and periductal lymphocytic accumulation (Figure 3). At the margins of the lesion there was a very minor amount of ductal proliferation and intraductal papillary hyperplasia (Figure 4) and oedema of the adjacent stroma.

\section{Discussion}

The pathological features of this case are very similar to those of the cystic hyperplasia commonly seen in the female breast. The minor marginal changes might 


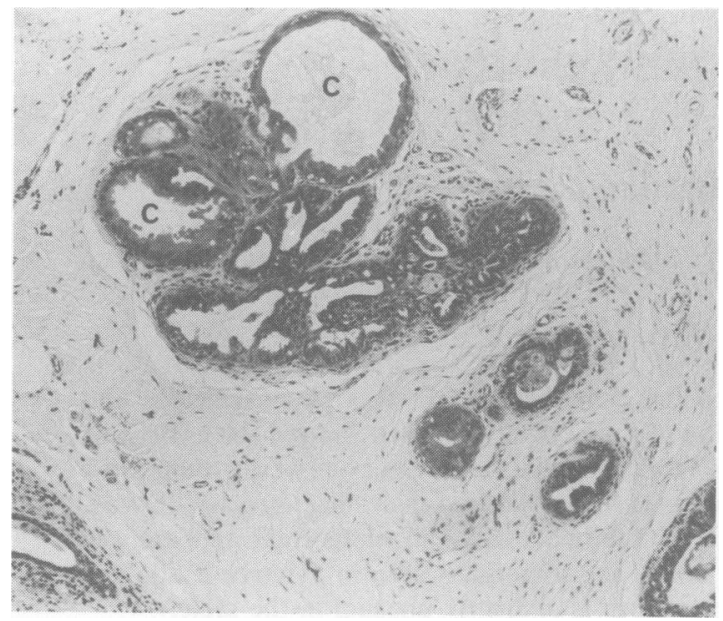

Figure 1 Small cyst formations (C) lined by apocrine type epithelium in a fibrotic background. HE $\times 125$.

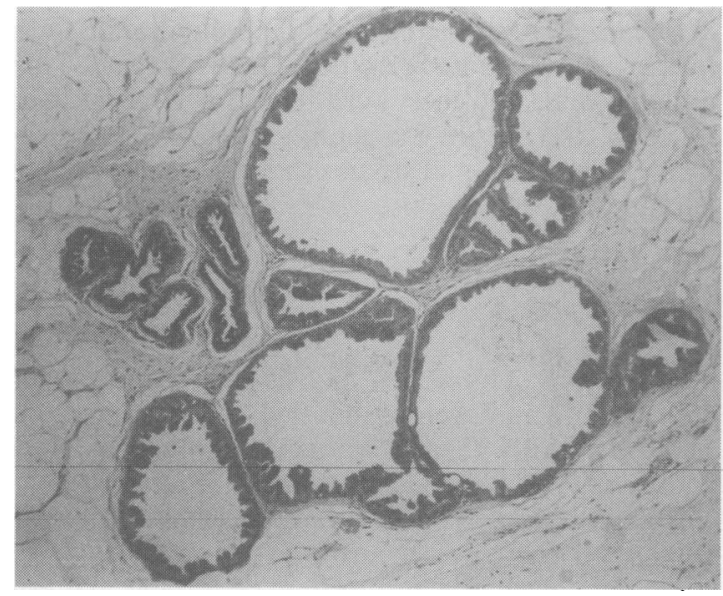

Figure 2 Dilated cysts grouped in a lobular pattern and showing extensive apocrine metaplasia. $\mathrm{HE} \times 250$.

suggest that there had been the more usual features of gynaecomastia. In this latter the dominant features are ductal hyperplasia and periductal stromal changes. Less commonly, lobule formation and lobular hyperplasia may occur in gynaecomastia (Bannayan \& Hadju, 1972). In the present case the striking features are the extensive apocrine metaplasia and the grouping of cysts in a lobular arrangement.

Changes identical to a florid female type cystic hyperplasia have never been previously described and documented in the male breast. This case is additionally interesting in that features of mammary duct ectasia were also present. This condition has been previously

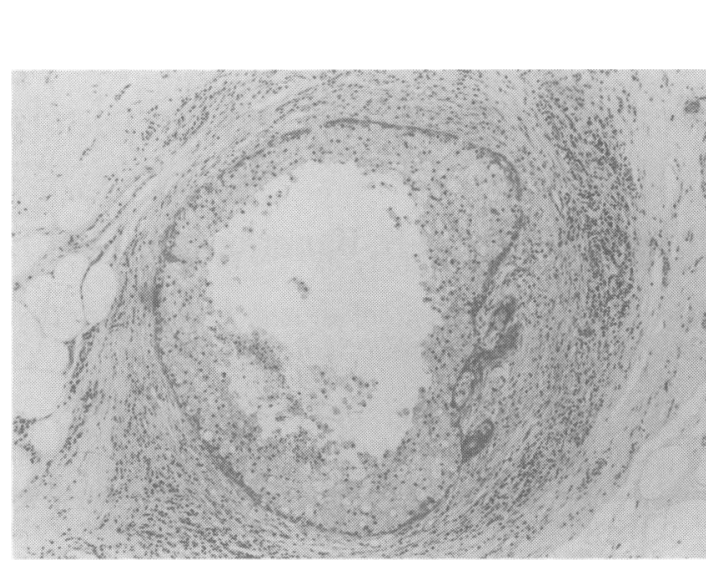

Figure 3 Dilated duct lined by foam cells and surrounded by a periductal lymphocytic infiltration. HE $\times 250$.

described in the male but it is very uncommon in thato only four examples have been described (Tedeschi \& McCarthy, 1974; Mansel \& Morgan, 1979).

It is reasonable to postulate that the present case began as a gynaecomastia with extensive lobularo formation which later underwent cystic change withN focal hyperplasia and apocrine metaplasia. Against this, however, is the fact that lobules not exhibiting either of these changes were not observed. Bannayane \& Hadju (1972), in their extensive review of 351 cases of histologically proven gynaecomastia, noted that $\stackrel{\oplus}{\rightarrow}$ pubertal and hormone-induced disease tended to be bilateral and diffuse whilst idiopathic and non-hor- 
monal drug-induced lesions were usually unilateral and discrete. Our patient, in view of the results of the clinical features, the biochemical and other investigations, falls into the category of idiopathic disease, and it is emphasized that the lesion was unilateral.

Azzopardi (1979) regards cystic disease of the

\section{References}

AZZOPARDI, J.G. (1979). In Problems in Breast Pathology, p. 60. W.B. Saunders Co. Ltd., London.

BANNAYAN, G.A. \& HADJU, S.I. (1972). Gynecomastia: clinicopathological study of 351 cases. American Journal of Clinical Pathology, 57, 431.

HERNANDEZ, F.J. (1978). Leiomyosarcoma of male breast originating in the nipple. American Journal of Surgical Pathology, 2, 299.

MANSEL, R.E. \& MORGAN, W.P. (1979). Duct ectasia in the male. British Journal of Surgery, 66, 660.

PANTOJA, E., LLOBET, R.E. \& LOPEZ, E. (1976). Gigantic female breast as essentially a disorder of involution but points out that it occasionally occurs in young post-pubertal girls who have never been pregnant and concludes that in some cases other mechanisms of development must be operative. The histopathological features of the present case underline this latter point.

cystosarcoma phyllodes in a man with gynaecomastia. Archives of Surgery, 111, 611.

REINGOLD, I.M. \& ASCHER, G.S. (1970). Cystosarcoma phyllodes in a man with gynecomastia. American Journal of Clinical Pathology, 53, 852.

TEDESCHI, L.G. \& McCARTHY, P.E. (1974). Involutional mammary duct ectasia and periductal mastitis in a male. Human Pathology, 5, 232.

WALDO, E.D., SIDHU, G.S. \& HU, A.W. (1975). Florid papillomatosis of the male nipple after diethylstilbestrol therapy. Archives of Pathology, 99, 364. 